\title{
Objective function to Optimize Bending Stress at Critical Section of Asymmetric Spur Gear
}

\author{
Dr. J M Prajapati ${ }^{1}$, P A Vaghela ${ }^{2}$ \\ ${ }^{I}$ Department of Mechanical Engineering, Faculty of Technology \& Engineering, Baroda, Gujarat, India \\ ${ }^{2}$ Department of Mechanical Engineering, Government Polytechnic, Vadnagar, Gujarat, India
}

\begin{abstract}
Main objective of this paper is to optimize Bending stress at critical section, which is most important parameter in gear design. It must be low as low possible. Bending Stress optimize by all affected Parameters of asymmetric spur gear tooth at critical section of tooth. Objective function for bending stress at critical section has been developed to minimize/optimize bending stress at critical section thickness of asymmetric spur gear tooth. A programme has been developed in SciLab software with help of developed objective function to optimize the bending stress at critical section of an asymmetric spur gear. Result obtains from SciLab programme compared to ANSYS software and give comment on validation of developed objective function.
\end{abstract}

Keywords: Optimization, Asymmetric Spur Gear, Critical Section thickness, objective function

\section{Introduction}

There has been a lot of research activity on spur gears with asymmetric teeth. New gear designs are needed because of the increasing performance requirements, such as high load capacity, high endurance, low cost, long life, and high speed. In some applications gears experience only unidirectional loading. In this instance, the geometry of the drive side does not have to be symmetric to the coast side. This allows for the design of gears with asymmetric teeth. These gears provide flexibility to designers due to their non-standard design. If they are correctly designed, they can make important contributions to the improvement of designs of gears.

In a standard symmetric gear, both left and right sides of a gear tooth profile have same bending and contact strength. However, in most practical cases, both the forward and backward rotations are not always used for power transmission. Therefore, two sides of the gear toot hare functionally different for most gears. Even if one side (drive side) is significantly loaded for longer periods, the opposite side (coast side) is unloaded or slightly loaded for short duration only. Thus Asymmetric tooth are well suited for cases where the torque is transmitted mainly, in one direction.

\section{Asymmetric spur gear teeth}

An asymmetric spur gear drive means that larger and smaller pressure angles are applied for the driving and coast sides. The two profiles (sides) of a gear tooth are functionally different for many gears. The workload on one profile is significantly higher and is applied for longer periods of time than for the opposite one. The design of the asymmetric tooth shape reflects this functional difference.

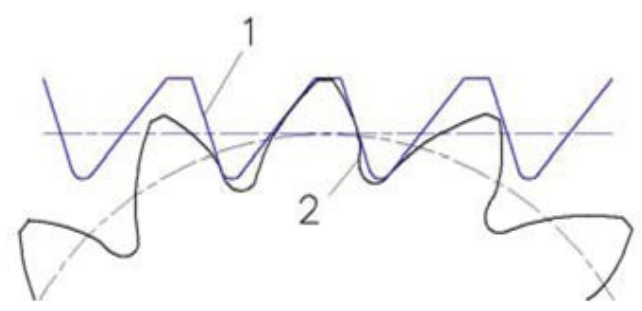

Fig. 1. Asymmetric spur gear

The design intent of asymmetric gear teeth is to improve the performance of the primary contacting profile. The opposite profile is typically unloaded or lightly loaded during relatively short work periods. The degree of asymmetry and drive profile selection for these gears depends on the application.

\section{Objective function to Optimize Bending Stress at Critical Section}

Optimization is a process that finds a best or optimal solution for a given problem.

An optimization is finding value of the variable that minimizes or maximizes the objective function while satisfying the constraints. 
The optimization problems are centered around three factors,

1. An objective function which is to be minimized or maximized

Bending stress at critical section is most important parameter in gear design. It must be low as low possible. It optimize by all affected Parameters of asymmetric spur gear tooth to reduce Bending Stress at critical section of tooth. So, objective function for bending stress at critical section must be minimized of asymmetric spur gear tooth to reduce Bending Stress at critical section of tooth.

2. A set of variables that affects the objective function.

As the pressure angle on drive side increases, the bending stress reduces at critical section of asymmetric spur gear. But Decision on maximum magnitude of drive side pressure angle is constraint by the safe contact ratio and tooth peaking effect. These way parameters are affecting directly or indirectly on performance we wants. There are so many parameters are likes Contact ratio, Top land tip thickness, Pressure angle on drive side profile, Pressure angle on coast side profile, Asymmetry factor, No. of teeth, Interference, Undercut, Centre distance, Gear ratio, Critical section thickness, Profile shift of pinion, Profile shift of gear, Module, Bending stress at critical section, Optimal fillet radius and Balance stress etc. affects the performance. So, it is necessarily to optimize these affected Parameters of asymmetric spur gear tooth to reduce Bending Stress at critical section of tooth.

3. A set of constrain that allow the unknown to that on certain value but exclude other.

As the pressure angle on drive side increases, the bending stress reduces at critical section of asymmetric spur gear. But Decision on maximum magnitude of drive side pressure angle is constraint by the safe $\varepsilon$ contact ratio. As the pressure angle on drive side increases, the bending stress reduces at critical section of asymmetric spur gear and Decision on maximum magnitude of drive side pressure angle is constraint by the safe contact ratio and Gear standard procedures such as IS, recommended that, its value is 1.1. Bellow this value, the loading period of a single gear tooth pair significantly increases, which is undesirable under cyclic loading conditions. $[5,7,8,9,13,17]$ As the pressure angle on drive side increases, the bending stress reduces at critical section of asymmetric spur gear and Decision on maximum magnitude of drive side pressure angle is constraint by the top land tip thickness and Gear standard procedures such as IS, recommended that, its value is should be greater than equal to 0.2 times the module for the hardened gears. Bellow this value, tip thickness decreases and tip becomes too sharp, more and more pointed. $[\mathbf{5 , 7}, \mathbf{9}, \mathbf{1 4}, \mathbf{1 5}, \mathbf{1 6}, \mathbf{1 7}]$ As the pressure angle on drive/coast side increases, the bending stress reduces. $[\mathbf{7}, \mathbf{1 1}, \mathbf{1 7}]$ The largest reduction in the bending stress can be found with (pressure angle on drive side profile) $\alpha \mathrm{d}>\alpha \mathrm{c}$ (pressure angle on coast side profile). [7]

Optimization means searching for, and finding, the best option. $\sigma(\min )=f\left(\varepsilon, S_{\text {tip }}, \alpha d, \alpha c, A F, N, G, S_{\text {crit }}, x p, x g, m, r f\right)$

Where,

$\alpha \mathrm{d}>\alpha \mathrm{c}$

$\varepsilon \geq 1.1$

$\mathrm{S}_{\text {tip }} \geq 0.2 * \mathrm{~m}$

\section{Development of objective function to optimize Bending Stress at critical section of asymmetric Spur gear.}

For this analysis following gear tooth parameters are used. Gears are used to transmit a power of $18 \mathrm{KW}$ at $1600 \mathrm{rpm}$.

\begin{tabular}{|c|l|l|}
\hline Sr. No. & \multicolumn{1}{|c|}{ Description } & \multicolumn{1}{c|}{ Value } \\
\hline 1 & Pressure angle, Coast side & $20^{0}$ fixed \\
\hline 2 & Pressure angle, Drive side & $20^{0}-40^{0}$ increment by $2^{0}$ \\
\hline 3 & Number of teeth & 25 and 47 \\
\hline 4 & Module & $4 \mathrm{~mm}$ \\
\hline
\end{tabular}

Table 1 Gear tooth parameter

With help of above parameters obtain data are

$\mathrm{Mt}=107429.588 \mathrm{Nmm}$

$\mathrm{Pt}=2148.5 \mathrm{~N}$

$\mathrm{dp}=100 \mathrm{~mm} \mathrm{rp}=50 \mathrm{~mm}$

$\mathrm{db}=93.96 \mathrm{~mm} \mathrm{rb}=46.98 \mathrm{~mm}$

$\mathrm{dt}=108 \mathrm{~mm} \mathrm{rt}=54 \mathrm{~mm}$

The maximum bending stress at critical section of the gear tooth root may be expressed as, Spur gear tooth bending stress as per Lewis [8]

$$
\sigma=\frac{M c}{I}
$$


Where

$M c=\left(P n x \cos \alpha_{f} \times h_{\text {crit }}-P v x e\right)$

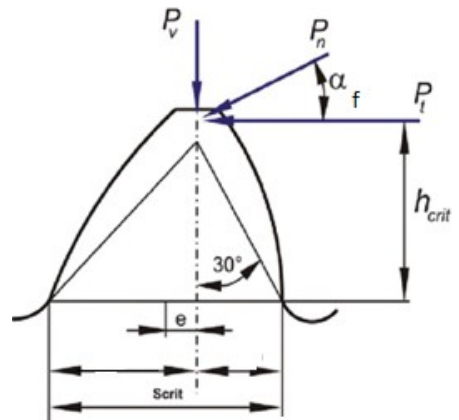

Fig.2 load on tooth

$P v=\frac{P n}{\sin \alpha_{f}}$

$M c=\left(P n x \cos \alpha_{f} x h_{c r i t}-P n x \sec \alpha_{f} x e\right)$

$I=\frac{b x S^{2} c r i t}{6}$

$p_{n}=\frac{P t}{\cos \alpha_{c}}$

$\sigma=\frac{P t}{b}\left[\frac{6\left(h_{c r i t} \cdot \cos \alpha f-e \cdot \sec \alpha f\right)}{s^{2}{ }_{c r i t} \cdot \cos \alpha c}\right]$

$\sigma=\frac{P t}{b \cdot m}\left[\frac{6 \cdot\left(\frac{h_{c r i t} \cdot \cos \alpha f}{m}-\frac{e \cdot \sec \alpha f}{m}\right)}{\left(\frac{S_{c r i t}^{2}}{m^{2}}\right) \cdot \cos \alpha c}\right]$

$\sigma=\frac{P t}{b \cdot m \cdot Y F}$

Where

$Y F=\left[\frac{\left(\frac{S^{2}{ }_{c r i t}}{m^{2}}\right) \cdot \cos \alpha c}{6 \cdot\left(\frac{h_{c r i t} \cdot \cos \alpha f}{m}-\frac{e \cdot \sec \alpha f}{m}\right)}\right]$

YF is the LF for asymmetric gear teeth.

$\sigma=\frac{P t}{b \cdot m \cdot Y F}$

$\sigma=\frac{2148.59}{40.4 . Y F}$

$\sigma=\frac{13.43}{. Y F}$

We know, 


$$
Y F=\left[\frac{\left(\frac{S^{2}{ }_{c r i t}}{m^{2}}\right) \cdot \cos \alpha c}{6 \cdot\left(\frac{h_{c r i t} \cdot \cos \alpha f}{m}-\frac{e \cdot \sec \alpha f}{m}\right)}\right]
$$

$\alpha c$ is pressure angle at Coast side profile and it is $20^{\circ}$ degree and $\alpha f$ load application angle is also $20^{\circ}$ degree and it is constant because bending stress compared for different pressure angle.

$$
Y F=\left[\frac{\left(\frac{S^{2}{ }_{c r i t}}{4^{2}}\right) \cdot \cos 20}{6 \cdot\left(\frac{h_{c r i t} \cdot \cos 20}{4}-\frac{e \cdot \sec 20}{4}\right)}\right]
$$

The proposed International standards organization (ISO) method of gear rating for tooth strength uses the $30^{\circ}$ angle. [23] Critical section always appears at the point determinined by $30^{\circ}$ tangents irrespectively of all the other tooth parameters.

With help of fig 3

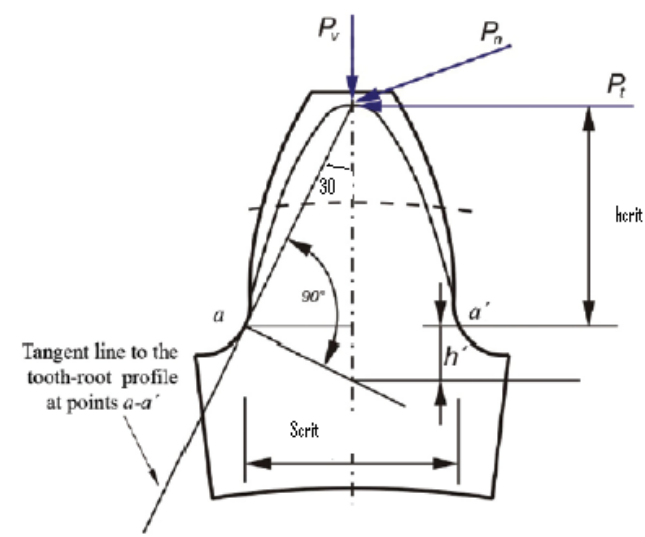

Fig. 3 critical section appears at $30^{\circ}$ tangents

$\mathrm{h}_{\text {crit }}=0.866 \mathrm{~S}_{\text {crit }}$

$$
Y F=\left[\frac{0.05873 S^{2}{ }_{c r i t}}{1.22 S^{2}{ }_{\text {crit }}-4.385 e}\right]
$$

But we know,

$$
\begin{aligned}
& e=\frac{S_{c r i t}-S_{\text {crit } 20}}{2} \\
& Y F=\left[\frac{0.05873 . S^{2}{ }_{c r i t}}{1.22 S_{\text {crit }}-2.169\left(S_{\text {crit }}-S_{\text {crit } 20}\right)}\right]
\end{aligned}
$$

Thickness of tooth at any radius $r$ thickness of tooth is calculated by following equations. [18]

$$
S_{r}=S_{r d}+S_{r c}
$$

Where,

$$
\begin{aligned}
& S_{r d}=r \cdot \theta \\
& S_{r c}=r \cdot \theta \\
& \theta=\frac{\pi}{2 . z}+i n v \alpha-i n v \alpha_{r} \\
& \alpha_{r}=\cos ^{-1}\left(\frac{r_{p}}{r} \cdot \cos \alpha\right)
\end{aligned}
$$

With help of above critical section thickness $S_{\text {crit }}$ is 


$$
S_{c r i t}=r_{b c}\left(\frac{\pi}{2 . z}+i n v \alpha_{c}-i n v \alpha_{b c}+\frac{\pi}{2 . z}+i n v \alpha_{d}-i n v \alpha_{b d}\right)
$$

For $S_{\text {crit } 20}$ pressure angle on drive side is $20^{\circ}$ degree. So with help of above equation

$$
\begin{aligned}
& S_{\text {crit } 20}=7.77 \text { so, } \\
& Y F=\left[\frac{0.05873 . S^{2}{ }_{c r i t}}{16.85-0.949 S_{\text {crit }}}\right]
\end{aligned}
$$

Put YF in equation 1

$$
\begin{aligned}
& \sigma=\left[\begin{array}{l}
\left.\frac{226.30-12.74 S_{c r i t}}{0.05873 \cdot S_{c r i t}^{2}}\right] \\
\text { Where, }
\end{array}\right. \\
& S_{c r i t}=6.6036+r_{b c}\left(i n v \alpha_{d}-i n v \alpha_{b d}\right) \\
& \alpha_{b d}=\cos ^{-1}\left(\frac{r_{p}}{r_{b}} \cdot \cos \alpha_{d}\right)
\end{aligned}
$$

This way bending stress at critical section is function of pressure angle of drive side profile of asymmetric spur gear tooth. So objective function is

$$
\begin{aligned}
& \sigma(\min )=\mathrm{f}(\alpha \mathrm{d}) \\
& \text { Where, } \\
& \\
& \alpha \mathrm{d}>\alpha \mathrm{c} \\
& \varepsilon \geq 1.1 \\
& \mathrm{~S}_{\text {tip }} \geq 0.2 * \mathrm{~m}
\end{aligned}
$$

\section{Development of programme for objective function to optimize Bending Stress at critical section of asymmetric Spur gear in SciLab Software.}

Scilab is software for numerical mathematics and scientific visualization. It is capable of interactive calculations as well as automation of computations through programming. It provides all basic operations on matrices through built-in functions so that the trouble of developing and testing code for basic operations are completely avoided. Its ability to plot $2 \mathrm{D}$ and $3 \mathrm{D}$ graphs helps in visualizing the data we work with. All these make Scilab an excellent tool for teaching, especially those subjects that involve matrix operations. Further, the numerous toolboxes that are available for various specialized applications make it an important tool for research. Scicos, a hybrid dynamic systems modeler and simulator for Scilab, simplifies simulations. The greatest features of Scilab are that it is multi-platform and is free. It is available for many operating systems including Windows, Linux etc.

Programme has been developed with help of above developed objective function to calculate bending stress at critical section of an asymmetric spur gear tooth.

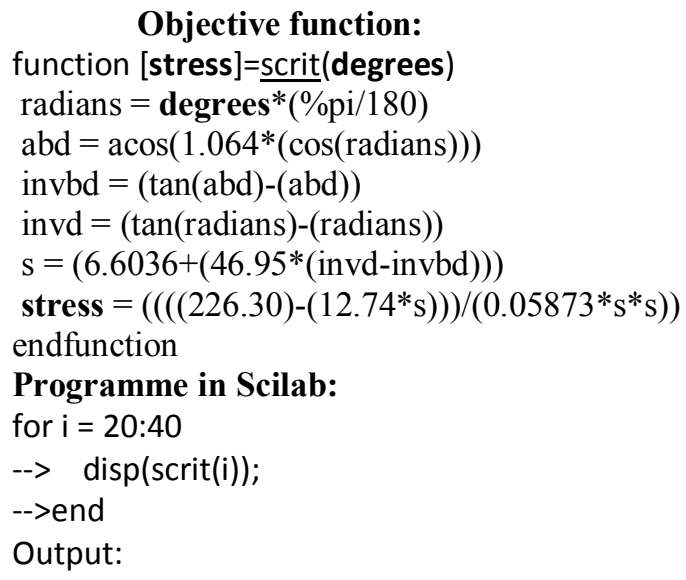




\begin{tabular}{|c|c|c|}
\hline Sr.No. & $\begin{array}{c}\text { Asymmetric gear of different pressure angle of drive } \\
\text { side profile }\end{array}$ & Bending Stress in MPa \\
\hline 1 & 20 & 42.539652 \\
\hline 2 & 22 & 39.942441 \\
\hline 3 & 24 & 37.795166 \\
\hline 4 & 26 & 35.855723 \\
\hline 5 & 28 & 34.049303 \\
\hline 6 & 30 & 32.337541 \\
\hline 7 & 32 & 30.696981 \\
\hline 8 & 34 & 29.111748 \\
\hline 9 & 36 & 27.570332 \\
\hline 10 & 38 & 26.063963 \\
\hline 11 & 40 & 24.585701 \\
\hline
\end{tabular}

Table 2 Bending Stress obtain from SciLab

\section{Bending Stress at critical section of asymmetric Spur gear in ASYS}

As a major part of present investigation a series of finite element analyses has been carried out for different pressure angle of drive side profile of asymmetric spur gears listed in table.1, subjected to a load at highest point of single tooth of contact (HPSTC). Gears are used to transmit a power of $18 \mathrm{KW}$ at $1600 \mathrm{rpm}$. A finite element problem is treated as plane stress with thickness problem and a solid 20-node95 bricks element are used to discredit the gear tooth domain.

The finite element method is capable of providing this information, but the time needed to create such a model is large. In order to reduce the modeling time, a preprocessor method that creates the geometry needed for a finite element analysis may be used, such as that provided by Pro/Engineer. Pro/Engineer can generate models of three-dimensional gears easily. In Pro/E, the geometry is saved as a file and then it can be transferred from Pro/E to ANSYS. In ANSYS, one can click File > Import > IGES > and check No disfeaturing and Merge coincident key points.

The first investigation involved a three-dimensional plane stress analysis for $4 \mathrm{~mm}$ module and $20^{\circ}$ pressure angle on both sides of the gears with 25 teeth and zero profile shifts. The gear tooth is considered to be a cantilever and it is constrained at the rim, an element supports the two degree of freedom and all the degrees of freedom are fixed. The gear tooth is loaded at HPSTC. The above meshed model, which is subjected to the boundary conditions and loading were statically analyzed and software performs the mathematical calculations and results are obtained in the post processing stage.

Similar analyses were carried out for different pressure angles on drive side. In the post- processor stage accepts the results and generates the contour plots for bending stress at the critical section. Obtain bending stress at critical section are shown below.

\begin{tabular}{|c|c|c|}
\hline Sr.No. & $\begin{array}{c}\text { Profile of asymmetrical spur gear } \\
\text { tooth }\end{array}$ & Bending stress in MPa \\
\hline 1 & $20-20$ & 41.73 \\
\hline 2 & $20-22$ & 41.39 \\
\hline 3 & $20-24$ & 43.98 \\
\hline 4 & $20-26$ & 37.93 \\
\hline 5 & $20-28$ & 36.12 \\
\hline 6 & $20-30$ & 33.76 \\
\hline 7 & $20-32$ & 32.54 \\
\hline 8 & $20-34$ & 32.65 \\
\hline 9 & $20-36$ & 26.38 \\
\hline 10 & $20-38$ & 25.46 \\
\hline 11 & $20-40$ & 22.64 \\
\hline
\end{tabular}

\section{Results and discussions}

From above data bending stress at critical section Vs pressure angle on drive side of asymmetric spur gear graph is developed to compare bending stress obtained from SciLab and ANSYS software 


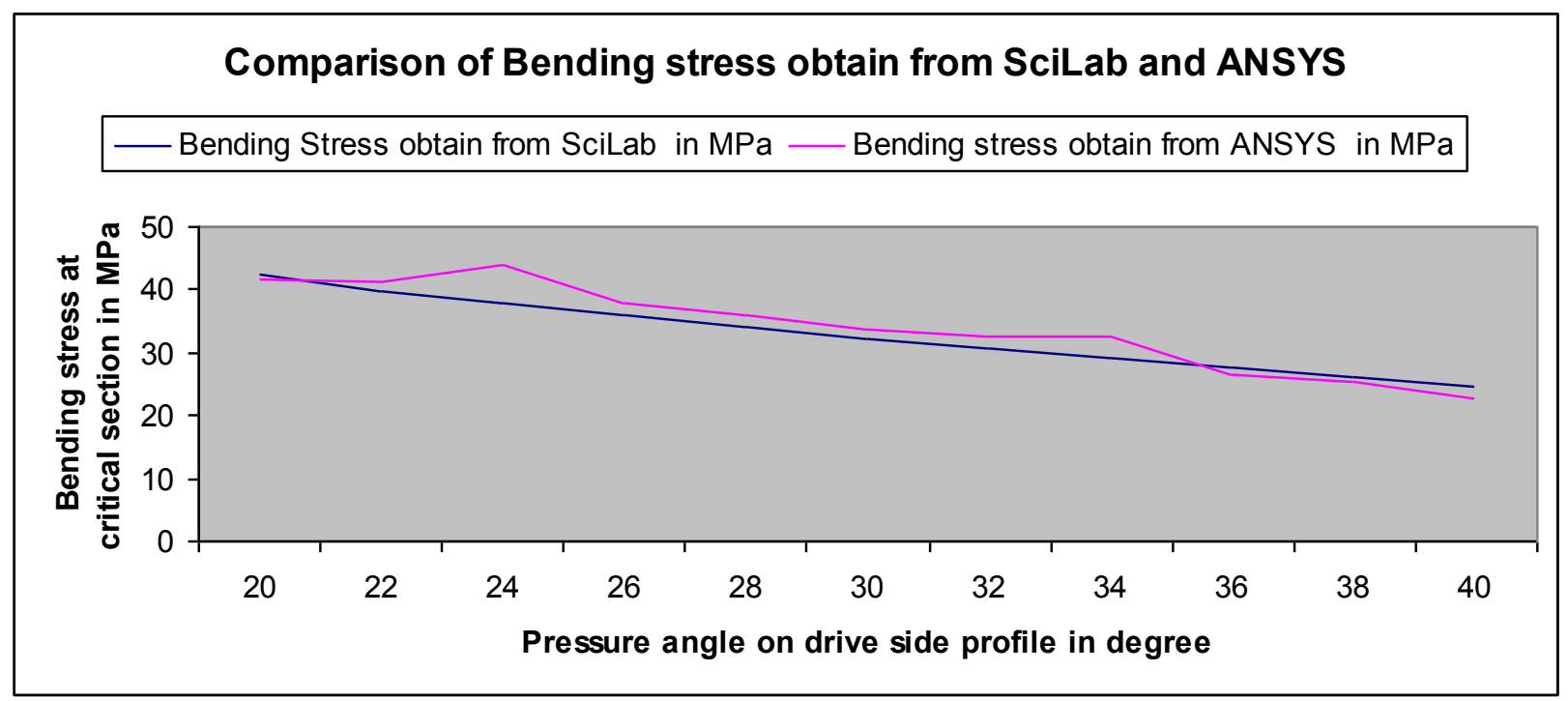

Fig. 4 Graph Bending stress Vs pressure angle on drive side gear tooth.

It was found that the bending stresses obtain from SciLab and ANSYS software also at the critical section reduces drastically with increases in the pressure angle on the drive side for certain limit.

Result obtains SciLab as well as ANSYS software are more or less similar. Bending Stress obtained from SciLab and ANSYS software are same which validate developed objective function for critical section thickness of asymmetric spur involute gear tooth.

\section{Conclusions}

Bending stress at critical section is most important parameter in gear design. It must be low as low possible. Objective function for bending stress at critical section has been developed to minimize/optimize bending stress at critical section thickness of asymmetric spur gear tooth. It show that bending stress at critical section is function of pressure angle of drive side profile of asymmetric spur gear tooth and it minimize/optimize bending stress under consideration of constraints. Programme has been developed with help of developed objective function to calculate bending stress at critical section of an asymmetric spur gear tooth and obtain result compare to result obtain from ANSYS software to validate the objective function. Result obtains from SciLab as well as ANSYS software is more or less similar. Bending Stress obtained from SciLab and ANSYS software are same which validate developed objective function for critical section thickness of asymmetric spur involute gear tooth.

\section{PAPERS}

\section{References}

[1] Alexander Kapelevich "Geometry and design of involute spur gears with asymmetric teeth" Mechanism and Machine Theory 35 (2000) 117 to 130

[2] Faydor L. Litvin, Qiming Lian, Alexander L. Kapelevich "Asymmetric modified spur gear drives: reduction of noise, localization of contact, simulation of meshing and stress analysis" Computer Methods Applied Mechanics and Engineering. 188 (2000) 363 to 390

[3] Alexander L. Kapelevich and Yuriy V. Shekhtman” Direct Gear Design: Bending Stress Minimization” GEAR TECHNOLOGY, SEPTEMBER/OCTOBER 2003

[4] V. Senthil Kumar, D.V. Muni, G. Muthuveerappan "Optimization of asymmetric spur gear drives to improve the bending load capacity" Mechanism and Machine Theory 43 (2008) 829-858

[5] Singh Vedang and Senthilvelan S., "Computer Aided Design of Asymmetric Gear", 13th National Conference on Mechanisms and Machines (NaCoMM07),IISc, Bangalore, India, December 12-13, 2007

[6] Th. Costopoulos, V. Spitas "Reduction of gear fillet stresses by using one-sided involute asymmetric teeth", Mechanism and Machine Theory 44 (2009) 1524-1534

[7] Niels L. Pedersen "Improving bending stress in spur gears using asymmetric gears and Shape optimization" Mechanism and Machine Theory 45 (2010) 1707-1720

[8] Moya J.L., A.S. Machado, J.A.Velásquez, R. Goytisolo, A.E.Hernández, J.E. ernández, and J.M. Sierra "a study in asymmetric plastic spur gears", 2010

[9] Alexander Kapelevich and Yuriy Shekhtman" Area of Existence of Involute Gears"

[10] Alex Kapelevich, AKGears, LLC, 316 Oakwood Drive, Shoreview, MN 55126, USA," DIRECT DESIGN OF ASYMMETRIC GEARS: APPROACH AND APPLICATION", Proceedings of MPT2009-Sendai JSME International Conference on Motion and Power Transmissions May 13-15, 2009, Matsushima Isles Resort, Japan

[11] G. Mallesh, Dr. Math V B, Venkatesh, Shankarmurthy H J , Prasad Shiva P, Aravinda K "Parametric analysis of Asymmetric Spur Gear Tooth" 14th National Conference on Machines and Mechanisms (NaCoMM09),NIT, Durgapur, India, December 17-18, 2009

[12] A. Kapelevich and Y. Shekhtman," Tooth Fillet Profile Optimization for Gears with Symmetric and Asymmetric Teeth", American 
Gear Manufacturers Association, 500 Montgomery Street, Suite 350, Alexandria, Virginia 22314-1560.

[13] Konstandinos G. Raptis, Theodore N. Costopoulos,Georgios A. Papadopoulos and Andonios D. Tsolakis"Rating of Spur Gear Strength Using Photo elasticity and the Finite Element Method "American J. of Engineering and Applied Sciences 3 (1): 222 -231, 2010, ISSN 1941-7020

[14 Vaghela P A, Patel D A "Improvement of Load Carrying Capacity of Spur Gear by Asymmetric Teeth" the 5th International Conference on Advances In Mechanical Engineering-2011 (ICAME-2011) at Sardar Vallabhbhai National Institute of Technology, Surat during 6-8th June, 2011.

[15] Vaghela P A, Patel D A "Effect of rim thickness on asymmetric spur gear tooth bending stress" at National Conference on Recent Advances in Mechanical Engineering(NCRAME-2011) at R V R \& J C College of Engineering, Chowdavaram, Guntur, Andhra Pradesh, India during 7-8th July 2011.

[16] Vaghela P A, Patel D A "Optimize base on load carrying capacity and reduction in weight without compromising a bending stress at critical section of asymmetric spur gear" at International Conference on Design And Advances In Mechanical Engineering(ICDAAIME-2011) at S K P Collage of engineering, Thiruvannamalai, Tamilnadu, India -606 611 during 16-17th December 2011.

[17] J M Prajapati,P A Vaghela "factor affecting the bending stress at critical section of asymmetric spur gear" at International Journal Of Mechanical Engineering And Technology (IJMET), Volume 4, Issue 4, July - August (2013), pp. 266-273, ISSN 0976 - 6340 (Print) ISSN 0976 - 6359 (Online)

[18] J M Prajapati,P A Vaghela "Comparison of result of analytical and modeling software for critical section thickness, tip thickness of Asymmetric Spur Involute Gear Tooth" at International Journal of Engineering Research and Technology (IJERT), Vol. 2 , Issue 11, November -2013,pp 2245-2248, ISSN: 2278-0181.

BOOKS

[19] Nortan Robert, Dynamics of Machinery, IIIrd Edition, Prentice Hall of India

[20] Maitra Gitin M, Gear design, TMH Publication, New Delhi, IInd Edition, 1994

[21] Nortan Robert, Machine Design: Integrated Approach, IInd Edition, Pierson Education, 2003

[22] Dudley Darle W, Handbook of Practical Gear Design, Ist Edition, CRC Press London, 2009

\section{THESIS}

[23] Vaghela P A, Patel D A "Effect of rim thickness on asymmetric spur gear tooth bending stress" Gujarat Technological University,Gujarat,India,2011 